1 Delbet, P, Bulletin et Mémoires de la Société Nationale de Chirurgie (Paris), 1924, 50, 1144.

2 Thompson, B W, and Read, R C, American fournal of Surgery, 1974, 128, 777 .

${ }^{3}$ Schwartz, S I, and Dale, W A, Archives of Surgery, 1958, 77, 439.

${ }^{4}$ Holubitsky, I B, and McKenzie, A D, Canadian Fournal of Surgery, 1964, 7, 277.

5 Warren, K W, Athanassiades, S, and Monge, J I, American fournal of Surgery, 1966, 111, 23.

6 Thorpe, M E C, Scheuer, P J, and Sherlock, S, Gut, 1967, 8, 435.

${ }^{7}$ Danzi, J T, Makipour, H, and Farmer, R G, American fournal of Gastroenterology, 1976, 65, 109

${ }^{8}$ Meyers, R N, Cooper, J H, and Padis, N, American fournal of Gastroenterology, 1970, 53, 527.

${ }^{9}$ Holdsworth, C D, et al, Quarterly fournal of Medicine, 1965, 34, 211.

10 Smith, M P, and Loe, R H, American fournal of Surgery, 1965, 110, 239.

${ }_{11}$ Bartholomew, L G, et al, New England fournal of Medicine, 1963, 269, 8.

${ }^{12}$ Hellstrom, H R, and Perez-Stable, E C, American fournal of Medicine, 1966, 40, 184.

13 Comings, D E, et al, Annals of Internal Medicine, 1967, 66, 884.

14 Waldram, R, et al, Lancet, 1975, 1, 550.

15 Elias, E, et al, Gastroenterology, 1974, 67, 907.

16 Ruskin, R B, et al, Archives of Internal Medicine, 1976, 136, 232.

17 Rankin, J G, Skyring, A P, and Goulston, S J, Gut, 1966, 7, 433.

18 Javett, S L, Lancet, 1971, 1, 810.

19 Wagner, A, Lancet, 1971, 2, 663.

\section{Will no one tell me what she sings?}

Wordsworth's line was once used by a physician to depict his surgical colleague's approach to auscultation. Contemporary cardiologists are, perhaps, less arrogant, and they admit their doubts about exactly what produces heart sounds. Techniques such as intracardiac phonocardiography and echocardiography have helped enormously in elucidating cardiac murmurs, but the empirical physiology of the heart sounds is still not clear. Though this may seem surprising, it should not be altogether unexpected when viewed against the problems of interpretation of the findings from any new techniques, and echocardiography is no exception. Nevertheless, we have made a little progress. ${ }^{1}$

The origin of the first heart sound is controversial, and there are two schools of thought. The classic theory, as enunciated by Leatham, ${ }^{2}$ attributes its major elements to vibrations from the closure of the atrioventricular valves: one burst of high frequency vibrations is caused by mitral valve closure and a second results from the tricuspid valve. This theory is opposed by Luisada ${ }^{3}$ and his co-workers, who attribute the first high frequency vibrations to the early phase of rise of left ventricular pressure rather than to mitral valve closure and the second vibrations to a left-sided rather than a right-sided eventnamely, ejection of blood into the root of the aorta.

Which of these conflicting views is correct? Echo-phonocardiographic studies in various cardiac abnormalities have strongly supported the classic view that the origin of the first heart sound depends on mitral and tricuspid closure. But the source of the sound is now attributed to sudden deceleration of a mass of blood within the ventricle rather than to actual contact of the valves on closure. These studies have also shown the origin of aortic and pulmonary ejection sounds to coincide precisely with the maximal opening of these valves. ${ }^{1}$

As to the second sound, Rouanet's hypothesis of 140 years' standing 4 attributed this to closure of the semilunar valves, with both an aortic and pulmonary component. This has gone unchallenged until the recent echo-phonocardiographic studies of Chandraratna et al. ${ }^{5}$ These showed a delay between semilunar valve closure and the actual production of the second sound, suggesting that it may be a deceleration of a column of blood in the root of the aorta at the end of systole which causes the audible vibrations. The longer interval between pulmonary valve closure and sound production on the right side would be explained by the increased compliance of the pulmonary arteries. The matter remains unresolved but not uncontested; some workers still strongly support Rouanet's classical theory. ${ }^{1}$

Even the origin of the opening snap of the mitral valve (recognised by any medical student as the hallmark of the diagnosis of mitral stenosis) has been contested and attributed not to an opening event but in fact to reclosure of the valve. ${ }^{6}$ There is, however, little support for this theory, though admittedly the snap occurs simultaneously with the termination of the opening of the valve rather than with the pressure crossover between atrium and ventricle. ${ }^{1}$

What are ordinary doctors to make of all this? Despite the confusions some generalisations may be made. The first and second sounds, ejection sounds, clicks, and opening snaps are all high-frequency sounds, which on auscultation are characteristically sharp and short. Their production depends on the deceleration of a mass of blood producing vibrations of the heart chambers, valves, and contents. ${ }^{1}$ This concept does not include the lower frequency sounds-the third and fourth. sounds-which are probably produced independently of valve closure and result from rapid ventricular filling and altered ventricular compliance respectively. We hope that familiarity with comparatively new non-invasive investigatory techniques will provide more and possibly final answers to the remaining questions.

1 Criage, E, Circulation, 1976, 53, 207.

2 Leatham, A, Lancet, 1954, 2, 607.

3 Luisada, A A, et al, American Heart fournal, 1974, 88, 503.

${ }^{4}$ Rouanet, J, cited by McKusick, V A, in Cardiovascular Sound in Health and Disease. Baltimore, Williams and Wilkins, 1958.

${ }^{5}$ Chandraratna, P A N, Lopez, J M, and Cohen, L, Circulation, 1975, 51, 292.

${ }^{6}$ Rodbard, S, and Libanoff, A J, American Heart fournal, 1972, 83, 19.

\section{Ankylosing vertebral hyperostosis}

In 1950 Jacques Forestier and Rotes-Querol ${ }^{1}$ reported a condition predominantly affecting elderly men in which stiffness of the spine was associated with radiographic changes due to bony outgrowths arising from the anterolateral aspects of the vertebral bodies. Six years later a monograph ${ }^{2}$ published in English emphasised the distinction of this syndrome from ankylosing spondylitis. Ankylosing vertebral hyperostosis, well recognised in Europe, differs from ankylosing spondylitis in affecting men over the age of 50 , in its predilection for the dorsal spine, sparing the sacro-iliac joints, in the lack of pain and morning stiffness (it is frequently symptomless), and in the characteristic radiological picture. The spinal bony outgrowths may extend upwards, producing an appearance on the $x$-ray films like that of a candle flame, or downwards, giving a picture like that of candle wax dripping downwards. ${ }^{1-3}$ The two may join to form a continuous sheet of bone anterior to the vertebral bodies. Laboratory findings are usually negative, with normal sedimentation rates and serum calcium, phosphate, and alkaline phosphatase concentrations, but diabetes mellitus may coexist. Forestier's disease is essentially a radiological rather than a clinical syndrome, to be distinguished from paraspinal ossification in psoriatic arthropathy, 